\title{
The reproductive behaviour of an aphidophagous ladybeetle, Coccinella septempunctata (Coleoptera: Coccinellidae)
}

\author{
OMKAR* and SHEFALI SRIVASTAVA
}

Department of Zoology, University of Lucknow, Lucknow-226007 India; e-mail: omkaar55@hotmail.com

\begin{abstract}
Key words. Coccinellids, Coccinella septempunctata, reproductive behaviour, courtship and mating, mating duration, mate
\end{abstract} recognition

\begin{abstract}
The reproductive behaviour of a ladybeetle, Coccinella septempunctata was studied in detail. Males became sexually mature within $8.8 \pm 0.3$ days at $27^{\circ} \mathrm{C}$, while females took $11.2 \pm 0.4$ days. Males exhibited courtship display in five steps: approach, watch, examine, mount and copulatory attempt. A prominent rejection display was shown by certain females who had not matured sexually, had recently mated or were about to oviposit. Males appeared to recognize females through chemical and some visual cues, such as size and body shape, with the chemical cues possibly playing a more significant role. Multiple matings took place within the same day. There was a gradual decrease with time in reproductive parametres, such as the duration of copulation, the number of copulatory bouts and the latent period from first to subsequent matings on the same day. The interval between mating bouts slightly increased from first to subsequent matings. The sexual status of males and females affected the duration of copulation, which was greatest in the case of unmated males and virgin females. Multiple matings increased the oviposition period, fecundity and percent hatching of eggs.
\end{abstract}

\section{INTRODUCTION}

Mating and reproduction are essential to assure the survival of a species (Omkar et al., 2000; Omkar \& Pervez, 2002). Reproductive behaviour and its various aspects maximize the chances of survival of future generations. The efforts involved and the resources spent in progeny production are directly related to the fate of each organism in the long-term process of evolution.

The cosmopolitan, seven-spotted ladybeetle, Coccinella septempunctata Linnaeus (Coccinellidae: Coleoptera) has great economic importance due to its wide prey range, which includes a number of potential pests of agricultural and horticultural crops (Omkar \& Bind, 1993). Some information is available on the reproductive behaviour and performance of ladybeetles (Iwata, 1932; Kesten, 1969; Semyanov, 1970; Obata, 1987; Obata, 1988a, 1988b; Isogai et al., 1990; Obata \& Johki, 1991; Omkar \& Srivastava, 2001). Apart from a few reproductive aspects of $C$. septempunctata such as the maturation of testes (Isogai et al., 1990), mating duration (Obata \& Johki, 1991) and ovipositional preference for different substrata (Isogai et al., 1990; Omkar \& Srivastava, 2001), other important reproductive aspects remain unknown. The relative lack of information on the various aspects of reproduction has recently been highlighted in a review on the sexual activity in coccinellids (Hodek \& Ceryngier, 2000). We therefore studied the attainment of sexual maturity, mate recognition, courtship and mating behaviour, effect of sexual status of individuals on mating duration and effect of one, two and multiple matings on oviposition period, fecundity and percent hatching to fill this gap in knowledge.

\section{MATERIALS AND METHODS}

\section{To determine the pre-mating period}

Pupae of C. septempunctata were collected from fields around the city of Lucknow (India), from September 1997 to March 1998. A day after their emergence, adults were paired with sexually mature adults of the opposite sex ( 15 days old) and kept in glass Petri dishes $(9.00 \mathrm{~cm}$ diameter and height $2.5 \mathrm{~cm}$ ) with aphids, Lipaphis erysimi (Kaltenbach) and Aphis craccivora Koch on host plant twigs, Brassica campestris and Dolichos lablab, respectively, until maturation under laboratory conditions (temp. $25 \pm 5^{\circ} \mathrm{C}$ and R.H. $65 \pm 5 \%$ ). The adults were paired daily at $1000 \mathrm{hrs}$ and observed thereafter to see whether genital connection was established. The males and females were separated daily at $1800 \mathrm{hrs}$. This process was repeated daily till a proper genital connection was established and mating observed. The pairs were continuously observed for this time period, which was selected for convenience in observation. The females were re-paired daily with the same males. The premating periods of the male and female were taken as the maturity periods. The experiment was performed using ten replicates.

\section{To observe courtship behaviour}

Ten-day-old males and twelve-day-old females were taken from stock culture and kept in glass Petri dishes $(9.0 \times 3.5 \mathrm{~cm})$ with their natural prey on a host plant twig to observe courtship and mating behaviour under a binocular stereoscope (at 16 and 40X magnifications). Obata (1987) divided the male courtship behaviour of Harmonia axyridis in five steps: (i) Approach turning toward the live/dead body of a female from a distance of $1 \mathrm{~cm}$ or less, (ii) Watch - pausing at a distance of about $0.5 \mathrm{~cm}$ without any body contact, (iii) Examine - touching the opposite partner with his antennae and fore-legs, (iv) Mounting over the elytra of the female beetle, and (v) Copulatory attempt - bending the tip of abdomen downwards to fit into the genitalia of the female.

\footnotetext{
* Coresponding author.
} 
The time between the establishment of genital contact and first abdominal shaking is known as the "latent period" and the lateral abdominal shakings during mating are referred to as "bouts". Each bout comprises a number of units. The up and down body movements during bouts are termed as "strokes" (Obata, 1987). All the observations in this experimental subset were made in ten replicates.

\section{To study mate recognition (cues involved)}

Three female models were provided to each male ladybeetle as substitutes for a live female to study mate recognition cues. For this purpose, a sexually mature ( 10 days old) unmated male was introduced at the centre of a Petri dish $(9 \mathrm{~cm} \times 2.5 \mathrm{~cm})$ containing the model. The models were: (i) a freshly dead female (female was killed by placing cotton swab dipped in $70 \%$ alcohol on her head), (ii) a one-day-old dead female (collected from the stock culture), and (iii) a seven-day-old dead frozen female (collected from stock culture and frozen at $-10^{\circ} \mathrm{C}$ ). The male behaviour was studied and observations made (Obata, 1987) under a binocular stereoscope (at 16 and $40 \mathrm{X}$ magnifications). Ten observations were made for each type of model and a new male used each time.

\section{To study the effect of multiple matings on the same day}

Mature male (10 days old) and female ladybeetles (12 days old) were introduced into a glass jar (height $9 \mathrm{~cm} \times 13 \mathrm{~cm}$ diameter) with aphid-infested twigs. The number of matings in a day and the effect of the number of previous matings on the duration of copulation, bouts, latent period and the time interval between two bouts were observed. The behaviour of the two sexes during and after copulation was recorded. All the observations along with the mating and post-mating behaviour were made continuously from $1000 \mathrm{hrs}$ to $1800 \mathrm{hrs}$ in ten replicates.

\section{To study the effect of previous matings}

To observe the effect of male and female sexual status on the duration of copulation, the following pairs of ladybeetles were arranged and allowed to mate: (i) an unmated male with a virgin female, (ii) a copulated male with a virgin female, (iii) an unmated male with a mated female, and (iv) a copulated male with a mated female. The copulated males and females that were selected for the experiments had mated three times in the previous 24 hours. Five replicates were observed for each treatment.

\section{To study the effect of multiple matings}

To record the effect of one, two and multiple matings (i.e. more than five matings) on the oviposition period, fecundity and percent hatching, male and female ladybeetles were kept separately after emergence until they attained sexual maturity (10 days for males and 12 days for females) and then allowed to mate only once, twice or multiple times. The ladybeetles were separated daily after a single mating and the same pair reformed the next day for the next mating(s), as required. The females were maintained for their entire lifetime after mating to conclusively determine their oviposition period and fecundity. All the eggs were observed to allow calculation of the percent hatching of eggs. Ten replicates were made.

The data were analyzed using a one-way ANOVA and the comparison of means was done using Bonferroni's method using the software "Statistix-4.1".

\section{OBSERVATION AND RESULTS}

\section{The pre-mating period}

Males became sexually mature earlier than females at $27^{\circ} \mathrm{C}$. Males took a mean of $8.8 \pm 0.3$ days $(\mathrm{N}=10)$ after emergence before mating, while females took a mean of $11.2 \pm 0.4$ days $(\mathrm{N}=10)$. Females showed a prominent rejection display in the early days after emergence, before they finally mated. Reluctant females moved away from the male. In those cases where the male had a strong grip on the female, she raised her abdomen or kicked off the male with her hind legs.

\section{Courtship behaviour of the male}

Ten pairs of sexually mature (10-day-old males and 12day-old females) but unmated adults were observed. Courtship was male dominated and exhibited by the male alone. The males quickly approached the females from a distance of about $1 \mathrm{~cm}$ (approach), thereafter watched the females from the side without any body contact (watch) and examined by touching the antennae of the females with their antennae (examine). Following this, the males made copulatory attempts by climbing over the elytra of the females (mount), bent and finally inserted their aedeagus into the genitalia of the female ladybeetles (copulatory attempt) culminating in the commencement of mating.

\section{Mate recognition (cues involved)}

Males differed in their responses to different models of females. When a freshly dead female was introduced in a Petri dish containing the male, there was an increase in male movement and he approached the female. The male observed the dead female from all sides, but did not examine her by touching her mouthparts and antennae. The male ladybeetle directly mounted on the female elytra and tried to shake his body laterally and after 5-6 unsuccessful mating attempts, the male left the female. Seven out of ten males mounted the freshly dead females and three stopped after examining them and did not mount.

When a one-day-old dead female was provided to the male, he showed signs of approach by turning his direction of movement, but never came close to the female and always maintained a distance of more than $1.0 \mathrm{~cm}$ from the female. All ten males approached the one-day-old dead females but only three ventured near enough to watch and examine her. The rest of the seven males neither watched nor examined the female. When a completely dry seven-day-old dead and frozen female was placed with a male, none of the ten males approached, watched or examined the female; her presence was ignored.

\section{Effect of multiple matings on the same day}

The ladybeetles mated frequently in a single day (4-6 times) with an intervening period ranging from 10 to 45 min. Rejection of male advances by the female was observed during the intervening periods. The duration of copulation decreased significantly with subsequent matings on a single day from $81.80 \pm 3.93$ to $25.00 \pm 0.94$ $\min (\mathrm{F}=97.69 ; \mathrm{df}=9 ; \mathrm{P}<0.0001)$ (Table 1). The latent period also decreased significantly with an increase in the number of matings from $7.31 \pm 0.33$ to $3.84 \pm 0.25 \mathrm{~min}$ ( $\mathrm{F}=35.77 ; \mathrm{df}=9 ; \mathrm{P}<0.0001)$. After the completion of the latent period, the male started the bouts. During bouts, 
TABLE 1. Comparison of copulatory period, latent period, interval and number of bouts during first, second, third and fourth matings of C. septempunctata $(\mathrm{n}=10)$.

\begin{tabular}{lcccc}
\hline Matings in one day & $\begin{array}{c}\text { Copulatory period } \\
(\mathrm{min})\end{array}$ & $\begin{array}{c}\text { Latent period } \\
(\mathrm{min})\end{array}$ & Interval (sec) & No. of bouts per mating \\
\hline $1^{\text {st }}$ mating & $81.80 \pm 3.93^{\mathrm{a}}$ & $7.31 \pm 0.33^{\mathrm{a}}$ & $21.39 \pm 0.57^{\mathrm{a}}$ & $141.50 \pm 6.62^{\mathrm{a}}$ \\
$2^{\text {nd }}$ mating & $56.10 \pm 2.17^{\mathrm{b}}$ & $5.11 \pm 0.19^{\mathrm{b}}$ & $22.97 \pm 1.20^{\mathrm{a}}$ & $93.70 \pm 6.03^{\mathrm{b}}$ \\
$3^{\text {rd }}$ mating & $33.60 \pm 2.27^{\mathrm{c}}$ & $4.56 \pm 0.21^{\mathrm{bc}}$ & $23.72 \pm 1.20^{\mathrm{a}}$ & $52.20 \pm 3.90^{\mathrm{c}}$ \\
$4^{\text {th }}$ mating & $25.00 \pm 0.94^{\mathrm{c}}$ & $3.84 \pm 0.25^{\mathrm{c}}$ & $24.34 \pm 0.29^{\mathrm{a}}$ & $32.00 \pm 1.26^{\mathrm{d}}$ \\
F-value & $97.69^{*}$ & $35.77^{*}$ & $1.98^{* *}$ & $96.79^{*}$ \\
\hline
\end{tabular}

Values are mean \pm S.E.

Means followed by the same letter within a column are not signi ficantly different.

* Significant at $\mathrm{P}<0.0001$; * Significant at $\mathrm{P}<0.2$.

the male held the female with his first two pairs of legs and the hind legs were kept on the substratum for support and balance. In a regular pattern, the male first shook his abdomen laterally (3-5 units per bout) and then moved up and down for a while (1-2 strokes). Thereafter, he rested for a very brief period (interval), which increased with the subsequent matings but not significantly from $21.39 \pm$ 0.57 to $24.34 \pm 0.29 \mathrm{sec}(\mathrm{F}=1.98 ; \mathrm{df}=9 ; \mathrm{P}<0.2)$. There was a significant decrease in total number of bouts from first to fourth matings from $141.50 \pm 6.62$ to $32.00 \pm 1.26$ $(\mathrm{F}=96.79 ; \mathrm{df}=9 ; \mathrm{P}<0.0001)$. Thus, the copulatory period, latent period and number of bouts during first, second, third and fourth matings gradually decreased but the interval between the bouts slightly increased.

\section{Mating, termination and rejection displays}

These observations were made in all of the experimental set ups. The female sometimes moved around slowly with the male on her back at random to find a comfortable place where the tip of her abdomen was curved slightly upwards to facilitate mating. The male occasionally rubbed the female elytra with his mouthparts or hind legs during the course of mating. The male rubbed the two parameres (accessory genital organs present on either side of the aedeagus) onto the ventral surface of female abdomen.

During the last phase of mating, the male remained stationary for a few minutes $(2-4 \mathrm{~min})$. Thereafter the female showed termination display by kicking away the male ladybeetle. In the post-mating period, both the male and female ladybeetles cleaned their mouthparts and antennae with their forelegs. The females of C. septem-

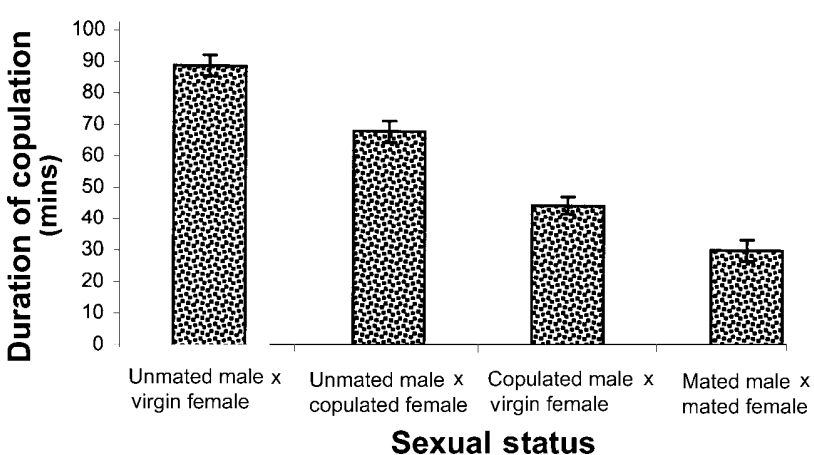

Fig. 1. Effect of sexual status on duration of copulation $(n=$ punctata were observed ejecting a spermatophore 1-3 hours after mating, though this was not a very regular feature. About $48.39 \%$ of the total females observed were found to eject the spermatophore, which was yellowish in colour with the consistency of a gel and was shaped like a balloon. It dried soon after ejection and was not consumed by the female. Females that had mated multiple times (4-6 times) ejected spermatophores more consistently $(79.56 \%)$ than the females, which had mated 2-3 times $(20.44 \%)$. Females that had mated only once were not observed ejecting a spermatophore.

It was also observed that a female rejected male advances when she had recently mated $(28.00 \pm 3.69 \mathrm{~min}$; range: $10-45 \mathrm{~min}$ ). Sometimes the females which rejected the male copulatory attempts laid eggs soon after $(17.00 \pm$ $1.87 \mathrm{~min}$ : range: $10-25 \mathrm{~min}$ ).

\section{Effect of previous matings}

The mean copulation period of unmated males with virgin females, unmated males with mated females, copulated males with virgin females and copulated males with mated females was $89.00 \pm 3.33,68.80 \pm 3.43,45.80 \pm$ 2.84 and $32.00 \pm 3.32 \mathrm{~min}$, respectively (Fig. 1). The longest copulation period was observed in unmated male copulated with virgin female $(89.00 \pm 3.33 \mathrm{~min})$ and the shortest duration was in case of mated male with mated female $(32.00 \pm 3.32 \mathrm{~min})$. The decrease in the copulatory period with change in the sexual status was statistically significant $(\mathrm{F}=60.47 ; \mathrm{df}=4 ; \mathrm{P}<0.0001)$.

\section{Effect of multiple matings on fecundity and hatchability}

The mean oviposition period was $5.00 \pm 0.42,8.00 \pm$ 0.49 and $24.50 \pm 1.17$ days, when the mating pairs of $C$. septempunctata were allowed to mate only once, twice and more than five times, respectively $(\mathrm{F}=185.47$; $\mathrm{df}=$ 9; $\mathrm{P}<0.0001$ ) (Fig. 2). The fecundity was $94.70 \pm 4.73$, $193.50 \pm 5.23$ and $705.50 \pm 6.02$ eggs with one, two and multiple matings, respectively $(\mathrm{F}=3754.21 ; \mathrm{df}=9 ; \mathrm{P}<$ 0.0001 ) (Fig. 3). The mean percent hatching of eggs was $77.72 \pm 2.14,88.59 \pm 1.07$ and $95.58 \pm 0.41$ percent after one, two and multiple matings, respectively $(\mathrm{F}=41.65$; $\mathrm{df}$ $=9 ; \mathrm{P}<0.0001)$ (Fig. 4). The oviposition period, fecundity and percent hatching were at a maximum in the case of multiple mating and a minimum in the case of a single mating. 


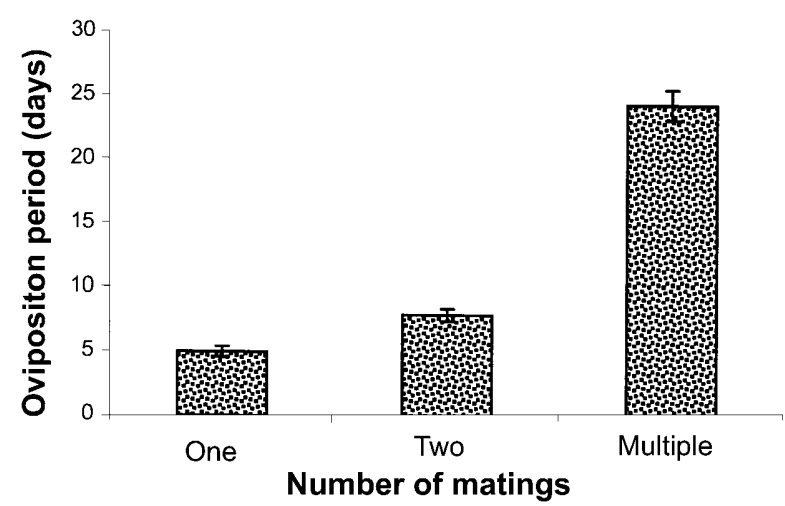
$10)$.

Fig. 2. Effect of number of matings on oviposition period $(\mathrm{n}=$

\section{DISCUSSION}

\section{The pre-mating period}

Adult $C$. septempunctata did not copulate for a number of days after emergence and this period may be recognized as the minimum duration required for sexual maturation. The long pre-mating period in males, despite their testicular follicles being mature even at emergence (Hodek \& Honěk, 1996), can also be attributed to the considerable time taken for the hardening of elytra in this ladybeetle (Hodek, personal communication). The long pre-mating period for females also reflects that they are not fit to reproduce immediately after emergence, probably due to the immature condition of their gonads. Pre-mating periods have also been recorded for $C$. septempunctata (Obata \& Johki, 1991), Harmonia axyridis (Obata \& Hidaka, 1987; Obata \& Johki, 1991), Cheilomenes sexmaculata (Obata \& Johki, 1991; Verma et al., 1993; Bind, 1998), Propylea japonica (Obata \& Johki, 1991), Scymnus nubilus (Kumar \& Chakraborty, 1997) and Adalia bipunctata (Hemptinne et al., 2001).

\section{Courtship behaviour and cues involved in mate recognition}

The small male ladybeetle is a relatively active individual and dominates the courtship behaviour. The male is possibly stimulated by chemical releases from the female ladybeetle. The courtship behaviour by the male ladybeetle is exhibited in five steps of approach, watch, examine, mount and copulatory attempt. The same steps, with the exception of examine, are displayed by a sexually mature male towards a freshly dead female probably

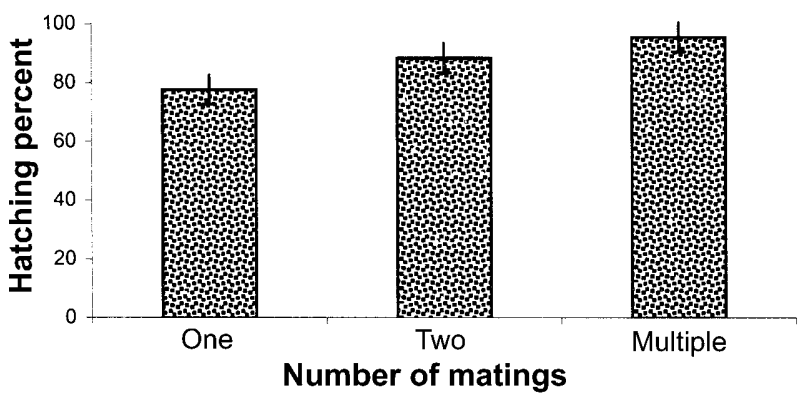

Fig. 4. Effect of number of matings on percent hatching of eggs $(n=10)$.

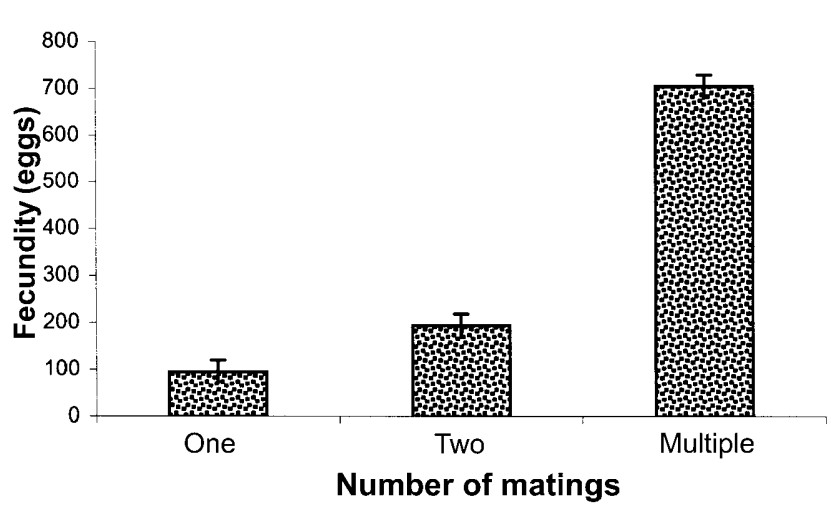

Fig. 3. Effect of number of matings on fecundity $(n=10)$.

still containing chemicals in her body. The approach behaviour was absent in the males when presented with a one-day old dead female, though a definite interest was observed through the presence of a marked orientation display. The seven-day old dead and frozen female was completely ignored. The quick approach of a male towards the freshly dead female suggests that the male possibly recognized the female through some chemical stimuli released by her, such as a sex pheromone, which stimulated a copulatory behaviour similar to that displayed towards a live female. Although the size and shape of the female dummy attracted the male, his behaviour with a one-day-old dead female suggested that he did not exhibit the complete range of courtship and mating behaviours, perhaps because of the absence of chemical factor in the female dummy. The orientation displayed suggests that visual cues were also helpful in mate finding, but it is the chemical cues which perhaps played a more important role in the final approach and subsequent mating. The absence of any prominent courtship behaviour towards the one-day dead female even in the presence of the visual cues lends further support to the hypothesis that chemical cues perhaps play a more important role than physical cues. The role of the visual cues is seen by the complete ignoring of the seven-day-old dead female, which was slightly discoloured and distorted. The pheromones released by the female along with the species-specific alkanes present on the elytra of ladybeetles probably play an important role in the recognition of mates using chemical stimuli (Hemptinne et al., 1998). On the basis of the results obtained it can be reasonably postulated that though the chemical and visual cues have a synergistic effect, it is perhaps the presence of an attractant chemical that leads to the culmination of courtship behaviour and consequently the mating. These findings are in agreement with behavioural observations on $H$. axyridis (Obata, 1987) and Tricholyga bombycis (Veerana \& Nirmala, 1989). Courtship behaviours of the male, such as watch, examine and touching the antennae of the female ladybeetle, was possibly in response to chemical stimuli released by the female. The male possibly received the chemical stimulus through olfactory receptors, which are mainly situated on their antennae. 
This hypothesis is also supported by the observations of Paraglenea fortunei (Wang et al., 1991).

\section{Multiple matings on the same day}

The decrease in the duration of copulation and the number of bouts suggested that these might probably be related to the physiological state of the male ladybeetle. The vigorous bouts are rigid and energy consuming activity and probably responsible for the sperm transfer into the genital tract of the female ladybeetle (Srivastava, 2000). Subsequent matings on a single day may lead to a state of exhaustion. This probably leads to an increase in the duration of the interval between bouts and the latent period. The decrease in interval is, however, not significant and this may be due to the comparatively less exhaustion induced by the significant reduction in copulatory period and number of bouts with successive matings. Somewhat similar observations have been made in $H$. axyridis (Obata, 1987). Similar to C. septempunctata, multiple matings were also recorded in other ladybeetles, viz. Adonia variegata, Scymnus quadrillum (Kapur, 1942), Thea cincta (Bagal \& Trehan, 1945), Nephus regularis (Rawat \& Modi, 1969) and C. sexmaculata (Verma et al., 1993; Bind, 1998).

The female terminated mating by kicking away the male with her hind legs after a pronounced period of mating, which suggests that the female initiates the termination of mating possibly after her satiation, as has also been pointed out by Wang et al. (1990). The observations made in due course of the experiment suggest that the female exhibits rejection display at the times when she was not sexually mature, had recently mated or was about to oviposit. Similar observations in ladybeetles have also been reported earlier (Majerus \& Kearns, 1989).

\section{Effect of previous matings}

That the longest mating duration occurred in the case of unmated males with virgin females showed that the sexual status of both the male and female affected the copulatory period. That the sexual status of the male has a pronounced effect on the duration of copulation can also be suggested. The maximum copulatory period in the case of mating between unmated males and virgin females suggested that possibly they were more vigorous than those of mated male and mated female ladybeetles. Similar findings were also reported in $H$. axyridis (Obata, 1987).

\section{Effect of multiple matings}

Once mated, females laid eggs in response to the first mating for a few days. As the number of matings increased, the duration of oviposition also increased. Although once mated females laid a considerable number of eggs, their fecundity increased greatly after multiple matings. Multiple matings increased the fertility, viability and percent hatching of eggs. This enhanced fecundity and egg viability is in response to the enhanced fertilization owing to the increased and more frequent supply of sperm (Srivastava, 2000). Similar findings have been reported for other ladybeetles, viz. A. bipunctata, $P$. qua- tuordecimpunctata and H. quadripunctata (Majerus, 1994) and C. montrouzieri (Kaufmann, 1996).

Thus, it can be inferred that: (i) the female C. septempunctata takes longer to mature than the male, (ii) the courtship behaviour is male dominated and displayed in five steps, viz. approach, watch, examine, mount and copulatory attempt, (iii) the female resists male advances when she is sexually immature, has recently mated or is about to lay eggs, (iv) chemical (pheromones) and visual cues have a synergistic effect on mate recognition and the former may possibly play a more defining role, (v) multiple matings on a single day showed a decline in the energy consuming processes of the mating due to exertion and subsequent exhaustion, (vi) unmated males and virgin females showed the most vigorous mating, and (vii) multiple matings led to increased oviposition period, fecundity and percent hatching.

ACKNOWLEDGEMENTS. The authors are thankful to the referees for providing valuable suggestions; Professor K.C. Pandey, Head, Department of Zoology, University of Lucknow, Lucknow-226 007 (India) for encouragements and to the Indian Council of Agricultural Research, New Delhi for providing financial assistance in the form of a research grant.

\section{REFERENCES}

BIND R.B. 1998: Bioecology and Behaviour of a Ladybird Beetle, Cheilomenes (= Menochilus) sexmaculata (Fabricius) (Coleoptera: Coccinellidae). Ph.D. Thesis. University of Lucknow, Lucknow, 164 pp.

BAGAL S.R. \& TREHAN K.N. 1945: Life-history and bionomics of two predaceous and one mycophagous species of Coccinellidae. J. Bombay Nat. Hist. Soc. 45: 566-575.

Hemptinne J.L., Lognay G. \& Dixon A.F.G. 1998: Mate recognition in the two-spot ladybird beetle, Adalia bipunctata: role of chemical and behavioural cues. J. Insect Physiol. 44: $1163-1171$.

Hemptinne J.L., Dixon A.F.G. \& Adam B. 2001: Do males and females of the two-spot ladybird, Adalia bipunctata (L.), differ in when they mature sexually? J. Insect Behav. 14: 411-419.

Hodek I. \& HonĚK A. 1996: Ecology of Coccinellidae. Kluwer Academic Publisher, Dordrecht, The Netherlands, 464 pp.

Hodek I. \& Ceryngier P. 2000: Sexual activity in Coccinellidae (Coleoptera): A review. Eur. J. Entomol. 97: 449-456.

IwATA K. 1932: On the biology of two large lady-birds in Japan. Trans. Kansai Entomol. Soc. 3: 13-26.

Isogar M., SAKuraI H. \& TAKedA S. 1990: Relationship between spermatogenesis and diapause in the ladybeetle, Coccinella septempunctata brucki Mulsant. Res. Bull. Fac. Agric. Gifu Univ. 55: 93-99.

KAPUR A.P. 1942: Bionomics of some Coccinellidae, predaceus on aphids and coccids in North India. Indian J. Entomol. 4: 49-66.

KaUfMann T. 1996: Dynamics of sperm transfer, mixing and fertilization in Cryptolaemus montrouzieri (Coleoptera: Coccinellidae) in Kenya. Ann. Entomol. Soc. Am. 89: 238-242.

Kesten U. 1969: Zur Morphologie und Biologie von Anatis ocellata (L.) (Coleoptera: Coccinellidae). Z. Angew. Entomol. 63: 412-455.

Kumar S.M.V. \& Chakraborty N. 1997: Biology of Scymnus nubilus Mulsant (Coleoptera: Coccinellidae), a native predator of pink mealy bug, Maconellicoccus hirsutus (Green) (Hemiptera: Pseudococcidae). J. Entomol. Res. 21: 329-334. 
MaJerus M.E.N. 1994: Female promiscuity maintains high fertility in ladybirds (Col.: Coccinellidae). Entomol. Mon. Mag. 130: 205-209.

Majerus M. \& Kearns P. 1989: Ladybirds. Richmond Publishing, England, 103 pp.

Oвата S. 1987: Mating behaviour and sperm transfer in ladybeetle, Harmonia axyridis (Pallas) (Coleoptera: Coccinellidae). Appl. Entomol. Zool. 22: 434-442.

Obata S. \& Hidaka T. 1987: Ejection and ingestion of the spermatophore by the female ladybird beetle, Harmonia axyridis Pallas (Coleoptera: Coccinellidae). Can. Entomol. 119: 603-604.

OватA S. 1988a: Mating behaviour and sperm transfer in the ladybird beetle, Harmonia axyridis Pallas (Coleoptera: Coccinellidae). In: Niemczyk E. \& Dixon A.F.G. (eds): Ecology and Effectiveness of Aphidophaga. SPB Acad. Publ., The Hague, pp. 39-42.

Oвата S. 1988b: Mating refusal and its significance in female of the ladybird beetle, Harmonia axyridis. J. Physiol. Entomol. 13: $193-199$.

OBata S. \& JohKi Y. 1991: Comparative study on copulatory behaviour in four species of aphidophagous ladybirds. In Polgar L., Chambers R.J., Dixon A.F.G. \& Hodek I. (eds): Behaviour and Impact of Aphidophaga. SPB Acad. Publ., The Hague, pp. 207-212.

OMKAR \& BIND R.B. 1993: Records of aphid-natural enemies complex of Uttar Pradesh. II. The Coccinellids. J. Adv. Zool. 14: 96-99.

Omkar, SRivastava S. \& James B.E. 2000: Mating rituals in insects. Everyman's Sci. 34: 192-199.

OmKar \& Pervez A. 2002: Reproduction in predatory ladybeetles: A review. In: Gupta V.K., Verma A.K. \& Sharma J.P. (eds): Perspectives in Animal Ecology and Reproduction. Vol. I. Daya Pub., Delhi, pp. 181-205.

OmKar \& SRIVAStaVa S. 2001: Ovipositional preference of a ladybeetle, Coccinella septempunctata Linn. (Coccinellidae: Coleoptera) amongst different substrata. J. Aphidol. 15: 5-8.

Rawat R.R. \& Modi B.N. 1969: Studies on Nephus regularis (Coleoptera: Coccinellidae) as a predator of striped mealybug in Madhya Pradesh. Ann. Entomol. Soc. Am. 62: 953-956.

Semyanov V.P. 1970: Biological properties of Adalia bipunctata L. (Coleoptera: Coccinellidae) in conditions of Leningrad region. Zashch. Rast. Vredit. Bolez. 127: 105-112 [in Russian.]

SRIVASTAVA S. 2000: Certain Aspects of Bioecology and Ethology of a Ladybeetle, Coccinella septempunctata Linnaeus (Coccinellidae: Coleoptera). Ph.D. Thesis. University of Lucknow, Lucknow, $160 \mathrm{pp}$.

Veerana G. \& Nirmala M.R. 1989: Courtship and mating behaviour of the uzifly, Tricholyga bombycis Deck. (Diptera: Tachnidae). Entomon 14: 85-89.

Verma G.C., Vyas R.S. \& Brar K.S. 1993: Biology of Menochilus sexmaculatus (Fabricius) (Coccinellidae: Coleoptera). J. Res. Punjab Agric. Univ. 30: 27-31.

WANG Q., ZENG W. \& LI J.S. 1990: Reproductive behaviour of Paraglenea fortunei (Coleoptera: Cerambycidae). Ann. Entomol. Soc. Am. 83: 860-866.

WANG Q., Li J.S., ZeNG W. \& YIN X. 1991: Sex recognition by males and evidences for female sex pheromone in Paraglenea fortunei (Coleoptera: Cerambycidae). Ann. Entomol. Soc. Am. 84: 85-89.

Received July 30, 2001; revised November 6, 2001; accepted January 25, 2002 